\title{
E-commerce effects for the sustainable development goals
}

\author{
Svetlana Revinova* \\ RUDN University, Miklukho-Maklaya str.6, 117198 Moscow, Russia
}

\begin{abstract}
Achieving sustainable development goals is the task of all countries, both developed and developing. At the same time, almost all countries are moving to a digital economy, with the core of e-commerce. The study aims to identify the connections between these two areas and analyze the effects that may arise as a result. The analysis showed that ecommerce is linked to 10 of the $17 \mathrm{UN}$ Sustainable Development Goals. For the most part, these effects are positive. However, to achieve the most positive impact, the interest of both Internet companies and consumers is required.
\end{abstract}

\section{Introduction}

In September 2015, during the United Nations Summit on Sustainable Development in New York, 193 UN member states officially adopted a new sustainable development agenda "Transforming our world: the 2030 Agenda for Sustainable Development". This plan includes 17 goals and 169 tasks [1]. The goal of this program is to improve the quality of life and prospects for humanity.

One of the goals of sustainable development is to ensure the transition to sustainable consumption and production patterns. Sustainable consumption and production involve promoting the efficiency of resource and energy use, constructing sustainable infrastructure, providing access to essential social services, ensuring green and decent jobs and a better quality of life for all. It involves engaging consumers through education and training initiatives on sustainable consumption and lifestyles. The UN plan assumes that the implementation of the action strategy for the transition to sustainable consumption and production patterns should be carried out with the participation of all countries, and developed countries should be the first, taking into account the development and potential of these countries.

At the same time, the government of all countries aims to develop the digital economy, which has a significant impact on all spheres of life. The digital economy is becoming the basis for the implementation of sustainable consumption. One of the critical elements of the digital economy today is e-commerce. Over the past few years, e-commerce has become an integral part of the global retail system. As Internet access overgrows worldwide, the number of online shoppers continues to grow every year. In 2020, more than two billion

\footnotetext{
* Corresponding author: revinova-syu@ $@$ rudn.ru
} 
people purchased goods or services online, and during the same year, Internet retail sales worldwide exceeded $\$ 4.2$ trillion [2].

E-commerce is the marketing, purchase, and sale of goods and services on the Internet. E-commerce growth is observed in all countries without exception, but it is growing especially rapidly in developing countries. In recent years, China has been the leader in ecommerce turnover in the world [3]. E-commerce includes the distribution and sale of goods and services over the Internet. The backbone of e-commerce is distributing goods, but today an increasing number of services are also provided online. The Covid-19 pandemic has given a new impulse to the growth of e-commerce, especially in areas such as education, medicine, etc.

As more and more shoppers move to the Internet, there are more and more opinions about the negative consequences of this transition. Still, at the same time, the positive aspects of this transition often go unnoticed $[4,5]$. While research results show that, for example, e-groceries are potentially more sustainable than traditional shopping, with 10$30 \%$ lower emissions [6]. Most researchers talk about the adverse effects of e-commerce in connection with product packaging. Packaging functions must progress with the new requirements of e-commerce (for example, an increase in the number of packaging materials for each product, an increased need for product protection, life management, environmental sustainability, etc.) [7]. There is quite a lot of research related to the environmental impact of the last mile, the final stage of delivery to the buyer. Research shows that clicking and collecting for those customers who live within 5 kilometers of a store is a much more sustainable way to shop. However, if that distance increases, the cars' emissions they are likely to use to travel to the store will exceed the emissions produced by the carrier, making online shopping more sustainable. Last mile logistics are becoming increasingly important with the growth of e-commerce, thus leading to inevitable changes in the functioning of modern cities and the potential consequences cannot be ignored $[8,9]$.

E-commerce can be influenced not only by Internet companies but by consumers themselves [10]. The carbon footprint that remains after the purchase depends on which choice of delivery, packaging, and fitting of goods they choose.

The purpose of this article is to determine the possible contribution of e-commerce to the achievement of sustainable development goals and to determine the positive or negative impact of e-commerce.

\section{Methods}

We used expert, statistical and comparative analysis; data analysis using methods of grouping, generalization, methods of classification, induction, deduction, analogy, comparison, formalization. The data for the study were open sources of information on the Internet and research presented in the scientific literature.

\section{Results and Discussion}

There are various approaches to analyzing and classifying the 17 UN Sustainable Development Goals (SDG) in modern literature. For example, the classification of the Goals by the "dimensions" of sustainable development [11], classification of SDG based on their significance for business [12], etc. After analyzing the connection between ecommerce and the achievement of sustainable development goals, we propose the following classification (Table 1). 
Table 1. The connection between e-commerce and achieving development goals

\begin{tabular}{|c|c|c|}
\hline $\begin{array}{l}\text { E-commerce can impact the } \\
\text { achievement of the SDGs }\end{array}$ & $\begin{array}{l}\text { The SDGs can } \\
\text { affect the } \\
\text { development of } \\
\text { e-commerce }\end{array}$ & $\begin{array}{c}\text { SDGs and e-commerce are not } \\
\text { linked }\end{array}$ \\
\hline $\begin{array}{l}\text { Goal 1. End poverty in all its forms } \\
\text { everywhere } \\
\text { Goal 2. End hunger, achieve food security } \\
\text { and improved nutrition and promote } \\
\text { sustainable agriculture } \\
\text { Goal 3. Ensure healthy lives and promote } \\
\text { well-being for all at all ages } \\
\text { Goal 4. Ensure inclusive and equitable } \\
\text { quality education and promote lifelong } \\
\text { learning opportunities for all } \\
\text { Goal 5. Achieve gender equality and } \\
\text { empower all women and girls } \\
\text { Goal 8. Promote sustained, inclusive and } \\
\text { sustainable economic growth, full and } \\
\text { productive employment and decent work } \\
\text { for all } \\
\text { Goal 10. Reduce inequality within and } \\
\text { among countries } \\
\text { Goal 12. Ensure sustainable consumption } \\
\text { and production patterns } \\
\text { Goal 13. Take urgent action to combat } \\
\text { climate change and its impacts } \\
\text { Goal 17. Strengthen the means of } \\
\text { implementation and revitalize the global } \\
\text { partnership for sustainable development }\end{array}$ & $\begin{array}{l}\text { Goal 9. Build } \\
\text { resilient } \\
\text { infrastructure, } \\
\text { promote inclusive } \\
\text { and sustainable } \\
\text { industrialization } \\
\text { and foster } \\
\text { innovation }\end{array}$ & $\begin{array}{l}\text { Goal 6. Ensure availability and } \\
\text { sustainable management of } \\
\text { water and sanitation for all } \\
\text { Goal 7. Ensure access to } \\
\text { affordable, reliable, sustainable } \\
\text { and modern energy for all } \\
\text { Goal 11. Make cities and human } \\
\text { settlements inclusive, safe, } \\
\text { resilient and sustainable } \\
\text { Goal 14. Conserve and } \\
\text { sustainably use the oceans, seas } \\
\text { and marine resources for } \\
\text { sustainable development } \\
\text { Goal 15. Protect, restore and } \\
\text { promote sustainable use of } \\
\text { terrestrial ecosystems, } \\
\text { sustainably manage forests, } \\
\text { combat desertification, and halt } \\
\text { and reverse land degradation and } \\
\text { halt biodiversity loss } \\
\text { Goal 16. Promote peaceful and } \\
\text { inclusive societies } \\
\text { sustainable for } \\
\text { provide access to justice for all } \\
\text { and build effective, accountable } \\
\text { and inclusive institutions at all } \\
\text { levels }\end{array}$ \\
\hline
\end{tabular}

We have identified one goal, the achievement of which is necessary for the further development of e-commerce and the growth of the e-market, Goal 9. Innovation and technological development have an impact on all areas of life. The Internet and mobile communications have become a necessity for almost the entire population of the planet. These two types of communication are at the core of e-commerce technologies. In 2019, $96.5 \%$ of the world's population was covered by one or another network of at least $2 \mathrm{G}$ standard, and more than $60 \%$ were Internet users [13]. The further growth of e-commerce is inextricably linked with the increase in the number of Internet users, the acquisition of digital skills by the population not yet involved in the Internet, and the introduction of new technologies into the business processes of internet companies. Without sustainable infrastructure and innovation, the future development of e-commerce will be weak. Today we are faced with apparent inequalities in infrastructure development. So the penetration of the Internet differs by region of the world (Fig. 1). 


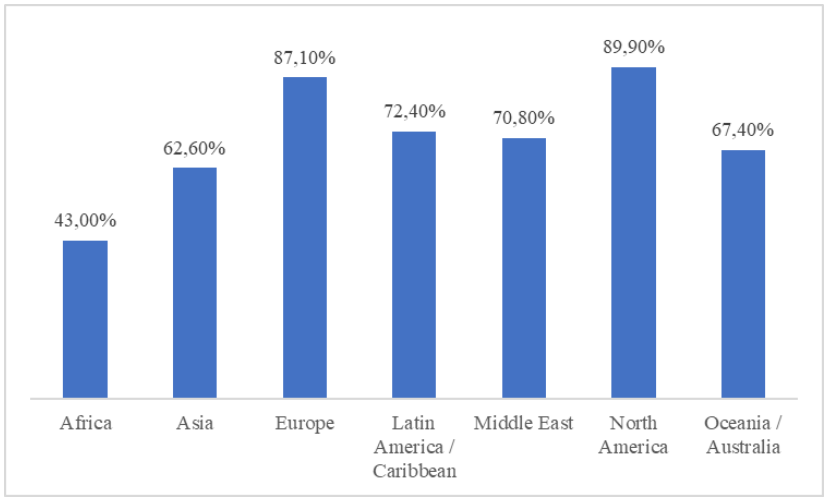

Fig. 1. Penetration of the Internet into the world's regions [14]

Let's take a look at 10 goals that e-commerce can impact. These impacts can be both positive and negative. Goal 1, on the one hand, can be partially achieved through the provision of new jobs by Internet companies. At the same time, participation in ecommerce requires costs, for example, on the Internet and communication devices. Also, poor citizens are more likely to lack the education and digital skills to participate equally in e-commerce.

Goal 2: End hunger, achieve food security and improved nutrition and promote sustainable agriculture. The e-commerce marketplace provides equal access to both businesses and consumers. Information on the Internet on food markets and food prices is becoming publicly available and timely.

One of the tasks of Goal 3 is universal health coverage, access to quality essential health services and access to safe, adequate, quality, and affordable essential drugs and vaccines for all. Today we see how the Covid-19 pandemic has changed consumer preferences in the electronic market. More and more internet users are turning to e-commerce to buy medicines. E-Health issues: the use of electronic communication technologies for patient care, health worker education, disease detection, and patient monitoring has become even more pressing. Medical and health centers have begun to provide electronic services more and more often.

Many educational Internet projects are now presented on the electronic market, starting with such well-known projects in mass online education as Coursera and ending with small projects of a narrow focus, for example, teaching children to draw. The Covid-19 pandemic has given a new impulse to the development of e-commerce projects in this area. Educational organizations that previously did not provide online services were forced to either introduce modern teaching methods and enter the electronic market or to close. Even the end of the pandemic will not stop the rapid growth of this segment of the electronic market. Today's schoolchildren and students have adapted to receiving education through the Internet and will undoubtedly use it throughout their lives. Simultaneously, educational organizations have realized the advantages of conducting educational activities online. For example, the absence of additional classrooms and handouts, the lack of restrictions on the size of groups, etc., will also use e-commerce projects more and more. It will contribute to the achievement of Goal 4: Ensure inclusive and equitable quality education and promote lifelong learning opportunities for all.

The contribution of e-commerce to Goal 8 and, in part, Goal 5 is linked to the labor market. E-commerce can influence these goals, as in goal 1, by providing equal access for all labor markets. The e-commerce market is a fast-growing market, and the need for new employees, from programmers to couriers, is very high. On popular job search sites, vacancies are created every day to find professionals selling goods and services on the 
Internet. The demand for employees exceeds the supply since the new field has not yet been fully mastered by young specialists. E-commerce projects have generated many unique specialties: web designers, web analysts, SMM marketers, etc. The most popular professional fields are internet marketing, performance advertising, social media marketing management, loyalty programs, and purchasing.

Goal 10: reduce inequality within and among countries. Inequality between countries is determined by many factors and often has historical roots. Developing countries are trying to overcome the lag behind developed countries through intensive development based on institutions, technologies, and the population's quality of life. Inequality within and between countries is a constant cause of concern for national leaders. Such inequality leads to social tensions, and vulnerable segments of the population become increasingly vulnerable. Ecommerce provides an opportunity to provide access to essential services for all parts of the people, both domestically and internationally. But achieving this e-commerce effect requires equal access to technology and infrastructure. So, in Russia, we note a different level of Internet penetration in the subjects of the Russian Federation. In other regions of Russia, we see different levels of digital skills. E-commerce is also developing unevenly.

As already mentioned, the e-commerce market has neither geographic nor time limitations. It operates 24 hours 7 days a week and can be accessed by any company or country resident with access to the Internet. Electronic commerce can significantly increase the exports of developing countries and ensure timely provision of all least developed countries with market access according to the decisions of the World Trade Organization. E-commerce can help strengthen the means of implementation and revitalize the Global Partnership for Sustainable Development, in line with Goal 17.

According to experts, the most significant contribution of e-commerce is achieving goals 12 and 13, related to each other. Sustainable consumption and production aim to do more and better with less costly resources. They also aim to overcome the direct relationship between economic growth and environmental degradation, improve resource efficiency and promote more sustainable lifestyles.

Distribution, packaging and return of online goods are considered to be the primary source of carbon emissions. Online shopping needs to be greener. It requires measures from the outside, both on Internet companies and the Internet buyers themselves.

Each product delivered from an online store has individual packaging, most often a plastic bag or even several bags. If customers order the same product in several sizes at once, they use their packaging. Every day, thousands of trucks and cars deliver these goods to customers and take back unclaimed but already unpacked goods. It creates tons of carbon emissions. Online stores need to take a responsible approach to the type of packaging used and its quantity, giving preference to reusable packaging. For example, Zara moved away from paper and plastic packaging a few years ago. Items are shipped in a recycled carton and are not individually packed, significantly reducing waste. These boxes can then be reused for storage or easily recycled. Also, the product must be packed in boxes of suitable size. New technologies such as additive manufacturing and 3D printing can help optimize the volume and shape of the packaging, thereby contributing to greener production, such as by reducing $\mathrm{CO} 2$ emissions. Currently available technologies can help rethink the whole paradigm of e-commerce packaging, which has changed very little over the past few decades [15].

Amazon, which delivers more than 10 billion units a year, said it emitted 44.4 million metric tons of carbon dioxide last year, which is about $85 \%$ of Switzerland's or Denmark's emissions. Nearly a third of U.S. solid waste comes from e-commerce packaging. To measure its carbon footprint, Amazon looked at emissions from all of its businesses, including the planes it operates and the energy it uses to produce Echos, Kindles, and its other devices. Amazon even included customer trips to its grocery chain Whole Foods [16]. 
These are the results of only one company. The most successful Russian company Wildberries in 2019 delivered 1,1 billion goods to customers, $400000 \mathrm{~km}$ was the average mileage of one truck. During the day, the truck covered about $1070 \mathrm{~km}$. Each car transported nearly 2 million pieces of goods per year [17]. At the same time, no one yet considers the carbon footprint left by online shoppers when searching for goods. One request for information on Google leaves the same carbon footprint as one boiled kettle of water or a 16-meter trip by car.

The mailing of letters by Internet companies also leaves no trace for the environment. Billions of e-mails consume the same amount of energy every day as heating 2 million American homes. The associated greenhouse gas emissions are comparable to the emissions of 3 million cars. When sending one letter, four grams of carbon are formed, and if a picture is attached to the message, then the carbon footprint rises to 50 grams. Emissions when sending 65 e-mails - comparable to 1 kilometer of driving car [18].

Large companies have already begun to solve the emissions problem. For example, Amazon plans to achieve zero carbon emissions by 2040 and wants other companies to join it. Google intends to use only carbon-free energy sources by 2030 . Google said it has been eliminating the company's carbon footprint since 1998, becoming the first company to achieve zero carbon emissions in 2007 and entirely switching to renewable energy since 2017 [19]. Many well-known brands have switched to packaging products with more environmentally friendly materials and less harmful delivery methods, which often leads to higher prices for the product.

Nevertheless, a lot depends on Internet companies. For example, Green Courier and DPD use bicycles and electric vehicles for delivery. Electric cars reduce greenhouse gas emissions by $17 \%$ (in the case of $20 \mathrm{~km} /$ day) to $54 \%$ (in the case of $120 \mathrm{~km} /$ day), or even more if the daily mileage increases [20].

The more retailers educate their customers about the environmental impact of their purchases and possible ways to reduce damage, the more likely they are to choose these greener options. One of the options for more rational consumption is to refuse express delivery. Suppose the online store must deliver the package to the buyer as quickly as possible. In that case, he will not wait for the full load of the car, while with standard delivery, the courier can deliver several packages in one trip, which significantly reduces the carbon footprint of the last mile. Pick-up points are becoming more and more popular in Russia. Delivery to pick-up points can increase the time but has a positive effect on the environment. In this case, the online store can deliver multiple orders at one time. In addition, in courier delivery, there are situations where the courier is forced to come a second time if the buyer is not at home, which doubles the carbon emissions. In using pickup points, the buyer picks up his order at a convenient time for him. Informing the environmental and social impacts of last mile delivery affects e-commerce customers and encourages them to choose more sustainable last-mile delivery [21].

The free return service is attractive to buyers. However, many returned goods go to landfills and pollute the environment. Returns are currently costing retailers $£ 60$ billion a year, with fashion retailers having the highest return rate at $56 \%$. The damage to the environment is even more significant. Indeed, in the United States, recycling generates 5 billion pounds of landfill waste and 15 million tons of carbon emissions annually. It is equivalent to the amount of garbage generated by 5 million people a year [22]. Barclaycard study found that $30 \%$ of shoppers deliberately overfill and then return unwanted items [23]. Thus, if retailers refuse a free return, shoppers might reject to order additional products. Ecommerce can become more environmentally sustainable by encouraging consumers to reduce purchases and increase the number of items in each delivery [24]. Content on ecommerce websites must contain detailed product descriptions and product illustrations. Websites should provide objective, complete and valuable information about products to 
reduce the number of searches and create customer confidence in the correct choice [25]. Companies must do their utmost to ensure that the buyer does not need to order a size range of the same product or the need for a free return. New technologies, such as artificial intelligence or augmented reality, may gradually replace the need for face-to-face product fitting.

\section{Conclusion}

The analysis showed that the contribution of e-commerce to achieving sustainable development goals is relatively high. E-commerce can help achieve 10 of the 17 SDG in one way or another. E-commerce has a positive impact on the sustainable development of both individual countries and the world. This impact is especially evident in the labor market, as the number of Internet companies are overgrowing, and with them, the number of jobs increases. Most vacancies require some qualifications, but in 2020 we saw a rise in areas such as courier delivery, where additional education is not required. E-commerce offers opportunities for access from anywhere globally to the same market for education and health services. Often, these services obtained over the Internet are cheaper. It includes primary and additional education, advanced training, getting medical consultations via the Internet from specialists from other countries, etc. At the same time, e-commerce can have adverse effects on the environment. Searching, packaging, shipping and returning items purchased through online stores leave their carbon footprint. E-companies can affect their carbon footprint by using rational packaging and shipping methods, although this can come with additional costs. They can influence sustainable consumption by educating their customers about sustainable behavior and opportunities to reduce environmental pollution. E-companies can significantly reduce their negative contribution to sustainable development goals.

\section{Acknowledgements}

This paper has been supported by the RUDN University Strategic Academic Leadership Program.

\section{References}

1. Transforming our world: the 2030 Agenda for Sustainable Development, Department of Economic and Social Affairs, https://sdgs.un.org/2030agenda

2. Topic: E-commerce worldwide, Statista, https://www.statista.com/

3. S. Revinova. International Journal of Economic Policy in Emerging Economies, 12(4), 377 (2019)

4. T. Tokar, R. Jensen and B. Williams. Business Horizons, 64(3), 323 (2021)

5. G. H. Popescu. Economics, Management and Financial Markets, 10, 80 (2015)

6. C. Siragusa and A. Tumino. International Journal of Logistics Research and Applications (2021)

7. R. Alberto, S. Giulia, G. Mauro and M. Cristina. International Journal of Engineering Business Management, 6, 14 (2014)

8. M. Viu-Roig and E. Alvarez-Palau. Sustainability, 12(16), 6492 (2020)

9. D. Lazarevic, L. Švadlenka, V. Radojicic, M. Dobrodolac. Sustainability, 12 (2020) 
10. J. Oláh, N. Kitukutha, H. Haddad, M. Pakurár, D. Máté and J. Popp. Sustainability, 11(1), 89 (2018)

11. E. Zavyalova, E. Starikova. Journal of Law and Administration, 3, 107 (2019)

12. Novak K., Zajceva N. Rethinking Sustainability, BRICS Business Magazine, http://bricsmagazine.com

13. E. Tairova, Sustainable development (2021)

14. World Internet Users Statistics and 2021 World Population Stats, https://www.internetworldstats.com/

15. S. Escursell, P. Llorach-Massana, M. B. Roncero. Journal of Cleaner Production, 280 (2021)

16. A. News, Middle of the herd' no more: Amazon tackles climate change", 2021, https://abcnews.go.com/

17. Wildberries presented the results of 2019 in numbers, 2021, https://www.retail.ru/

18. How does one Google search affect the environment? - Digitark , https://digitark.ee/

19. Contribution to the future, Google Sustainability, https://sustainability.google/

20. C. Siragusa, A. Tumino, R. Mangiaracina, A. Perego, International Journal of Sustainable Transportation (2020)

21. B. Ignat, S. Chankov, International Journal of Logistics Management 31, 521 (2020)

22. J. Schiffer, Vogue Business (2021)

23. Press releases, Barclaycard, Home.barclaycard, https://home.barclaycard/

24. P. van Loon, L. Deketele, J. Dewaele, A. McKinnon, C. Rutherford, Journal of Cleaner Production, 106, 478 (2015)

25. L.Xiao, F. Guo, F. Yu, S. Liu. Sustainability 11, (2019) 